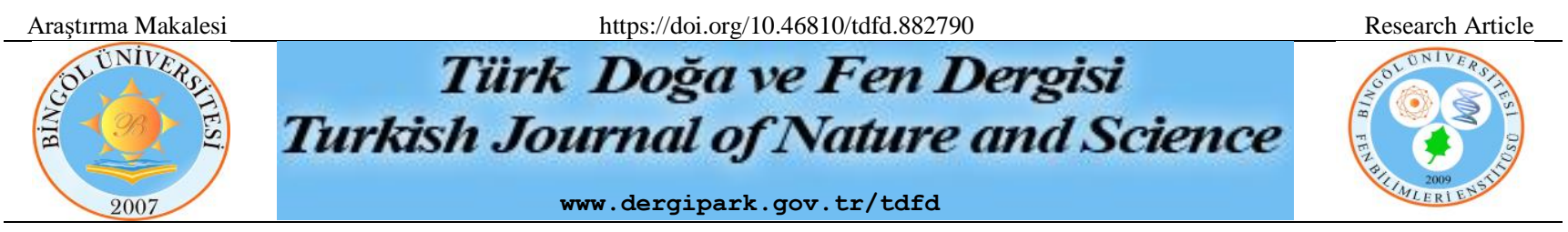

\title{
Asphodeline baytopiae'nin (Xanthorhoeaceae) Farklı Kısımlarından Elde Edilen Ekstrakların Antioksidan ve Enzim İnhibitör Özellikleri Üzerine Bir Çalışma
}

\author{
Gökhan ZENGìN ${ }^{1 *}$, Güneş AK ${ }^{1}$, Abdurrahman AKTÜMSEK ${ }^{1}$ \\ ${ }^{1}$ Selçuk Üniversitesi, Fen Fakültesi, Biyoloji Bölümü, Konya, Türkiye \\ Gökhan ZENGIN ORCID No: 0000-0001-6548-7823 \\ Güneş AK ORCID No: 0000-0002-9539-0763 \\ Abdurrahman AKTÜMSEK ORCID No: 0000-0002-5151-2650
}

*Sorumlu yazar: gokhanzengin@selcuk.edu.tr

(Alınış: 18.02.2021, Kabul: 26.04.2021, Online Yayınlanma: 31.12.2021)

\begin{abstract}
Anahtar
Kelimeler

Asphodeline

baytopiae,

Fenolikler,

Antioksidan,

enzim

inhibisyonu,

Doğal ajanlar
\end{abstract}

\begin{abstract}
Öz: Asphodeline Reichb. cinsi gıda ve ilaç kaynağı olarak büyük bir ilgiye sahiptir. Bu çalışmada, Asphodeline baytopiae Tuzlaci "nin (Xanthorhoeaceae) farklı kısımlarından (kök, gövde, yaprak ve tohum) elde edilen farklı çözücü ekstraktlarının (aseton, metanol ve su) biyolojik aktiviteleri belirlenmiştir. Biyolojik özellikleri için; antioksidan ve enzim inhibitör etkileri ortaya konulmuştur. Serbest radikal (DPPH ve ABTS), indirgeme gücü (CUPRAC ve FRAP), metal şelatlama ve fosfomolibdat testlerini içeren farklı antioksidan test sistemleri kullanılmıştır. Ayrıca, enzim inhibitör etkiler kolinesterazlar (AChE ve BChE), tirozinaz, $\alpha$-amilaz ve $\alpha$-glukozidaz'a karş1 araştırılmıştır. Bunlara ek olarak, her bir ekstraktın toplam fenolik ve flavonoid içerikleri de belirlenmiştir. Gövde-metanol ekstraktının en yüksek toplam fenolik (73.57 mg GAE/g ekstrakt) ve flavonoid (75.04 mg RE/g ekstrakt) içeriğine sahip olduğu görülmüş̧tür. Genel olarak, gövde ekstrakları; yaprak, kök ve tohum ile kıyaslandığında güçlü antioksidan yetenekler sergilemektedir. Kolinesteraz inhibisyon testlerinde, aseton ve metanol ekstraktlar inhibitör etkiler gösterirken, su ekstraklarının aktif olmadığı gözlenmiştir. Tirozinaz inhibitör etkileri 4.83 ile $74.64 \mathrm{mg} \mathrm{KAE} / \mathrm{g}$ ekstrakt arasında değişmektedir. $\alpha$-Amilaz ve $\alpha$ - glukozidaz inhisyonu sırasıyla $0.22-0.77 \mathrm{mmol}$ ACAE/g ekstrakt ve 3.42-4.65 mmol ACAE/g ekstrakt şeklindedir. Bu sonuçlar A. baytopiae'nin gıda ve farmasötik endüstrileri için doğal ajanların değerli bir kaynağı olarak düşünülebileceğini önermektedir.
\end{abstract}

\section{A Study on Antioxidant and Enzyme Inhibitory Properties of Extracts from Different Parts of Asphodeline baytopae (Xanthorhoeaceae)}

Keywords
Asphodeline
baytopiae,
Phenolics,
Antioxidant,
Enzyme
inhibition,
Natural
agents

Keywords Asphodeline baytopiae Enzyme Natural agents

\begin{abstract}
The Asphodeline Reichb. genus has a great interest as a source of drugs and foods. In the present study, we aimed to determine biological activities of different solvent extracts (acetone, methanol and water) from different parts (roots, stems, leaves, and seeds) from Asphodeline baytopiae Tuzlaci. Antioxidant and enzyme inhibitory effects were determined for biological properties. Different antioxidant assays including free radical scavenging (DPPH and ABTS), reducing power (CUPRAC and FRAP), metal chelating and phosphomolybdenum were employed. Enzyme inhibitory effects were investigated aganist cholinesterases (AChE and BChE), tyrosinase, $\alpha$-amylase and $\alpha$-glucosidase. In addition, total phenolic and flavonoid contents for each extracts were determined. Stem-acetone extract contained the highest levels of the total phenolics (73.57 $\mathrm{mg}$ GAE/g extract) and flavonoids (75.04 mg RE/g extract). Generally, stem extracts exhibited stronger antioxidant abilities when compared with leaves, roots and seeds. In cholinesterases inhbition assays, acetone and methanol extracts displayed inhibitory effects but water extracts were not active. Tyrosinase inhibitory effects varied from 4.83 to $74.64 \mathrm{mg} \mathrm{KAE} / \mathrm{g}$ extract. $\alpha$-Amylase and $\alpha$ - glucosidase inhibiton were $0.02-0.77 \mathrm{mmol} \mathrm{ACAE} / \mathrm{g}$ extract and 3.42-4.65 mmol ACAE/g extract, respectively. The results suggested that $A$. baytopae could be considered as valuable sources of natural agents in pharmaceutical and food industries.
\end{abstract}




\section{GíRIŞ}

Son yüzyılda insanoğlu salgınlar başta olmak üzere küresel boyutta birçok problem ile ciddi bir savaş halindedir. Yüzyılın başında görülen İspanyol gribi, ebola salgını gibi birçok hastalığın tedavisi gelişen teknoloji ile sağlanırken bulaşıcı olmayan diğer bazı hastalıkların görülme sıklığı günden güne artış göstermektedir. Örneğin günümüzde yaklaşık 500 milyon insan şeker hastalığı (diyabet) ile mücadele etmektedir [1]. Yine yapılan bir çalışmada Amerika'da 2019 yılında 55 milyon Alzheimer hastasının olduğu belirtilmiştir [2]. Bu noktadan hareketle insanoğlu belirtilen küresel problemlere karşı mücadele de acil eylem planlarına ihtiyaç duymaktadır. Artan nüfus ve hastalıkların yayılma hızı dikkate alındığında, bu savaşta sentetik çözümler halen birinci sıradadır. Ancak sentetiklerin kullanımına bağlı olarak ortaya çıkan başta toksik problemler olmak üzere istenmeyen yan etkiler bu kullanımları üzerine çeşitli toplumsal kaygıların doğmasına yol açmıştır. $\mathrm{Bu}$ bağlamda sentetiklerin yerine daha güvenli ve etkili doğal bileşiklere olan ilgi gün geçtikçe artmaktadır ve yeni doğal kaynakların belirlenmesine yönelik çalışmalar son yılların en ilgi çekici konularından biridir [3-4].

Türkiye florası bünyesinde bulundurduğu yaklaşık 12000 bitki taksonu ile doğal kaynaklar bakımından eşsiz bir hazine konumundadır [5]. Tarih öncesi çağlardan beri birçok uygarlığa ev sahipliği yapan ülkemizde bitkiler geleneksel Anadolu halk hekimliğinde oldukça önemli bir konuma sahiptir [6-8]. Bununla birlikte bu bitkilerin birçoğunun kullanımları hakkındaki bilimsel temeller halen eksiktir. Bu nedenle, yeni yapılacak çalışmalarla ülkemizin etnobotanik kimliğinin bilimsel verilerle doğrulanması büyük önem arz etmektedir.

Asphodeline Reichb. cinsi Xanthorrhoeaceae familyasına ait bir cins olup dünya üzerinde 19 takson ile temsil edilmektedir [9]. Üyeleri ülkemizde yöresel olarak kiriş veya çiriş otu olarak bilinen bu cins 18 tür (23 takson) ile temsil edilmektedir [10]. Bu taksonlardan 11'i ülkemiz için endemik olup, endemizm oranı \%61 şeklindedir [10]. Asphodeline üyeleri ülkemizde ve dünyada geleneksel olarak halk hekimliğinde oldukça önemli bir konuma sahiptir. Yapılan çeşitli çalışmalar bu durumu gözler önüne sermektedir. A. lıutea (L.) Rchb cinsin en yaygın üyesi olup gida ve tıbbi amaçlar için kullanılmaktadır [11, 12]. Ülkemizde yapılan çeşitli etnobotanik çalışmalarda da A. lutea 'nın yanı sıra çeşitli taksonların geleneksel amaçlarla kullanıldığı belirtilmiştir. Örneğin, Sargın ve Büyükcengiz [13]'in Gülnar ve çevresinde yaptıkları etnobotanik çalışmada $A$. baytopiae Tuzlaci 'nin yara ve egzama tedavilerinde geleneksel amaçlarla kullanıldığı rapor edilmiştir. Doğu Anadolu Bölgesinde benzer şekilde Asphodeline tenuior subsp. tenuiflora (K.Koch) Tuzlaci 'nın kökleri de yara tedavisinde halk hekimliğinde kullanılmaktadır [14]. Eraslan ve ark [15] Türkiye'de deri hastalıkları üzerine kullanılan bitkiler üzerine yaptıkları bir çalışmada $A$. baytopiae, A. brevicaulis (Bertol.) J. Gay ex Baker ve $A$. taurica (Pall.) Endl taksonlarının kullanımlarını da rapor etmişlerdir. Bunların yanı sıra, A. damascena (Boiss.) Baker, A. cilicica Tuzlaci ve A. globifera J. Gay ex Baker hemoroid ve kulak ağrılarının tedavisinde kullanılmaktadır [16, 17]. Bu kullanımlarına ek olarak, yapılan çeşitli çalışmalar Asphodeline cinsinin biyoaktif bileşikler bakımından oldukça zengin olduğunu ortaya koymuştur. Başta antrokinonlar, fenolik asitler ve flavonoidler olmak üzere çeşitli bileşikler bu çalışmalarda rapor edilmiştir [11, 18-24]. Yine yapılan çeşitli çalışmalarda Asphodeline üyelerinin antioksidan, antimikrobiyal, antikanser ve karaciğer koruyucu özellikler gibi biyolojik aktiviteleri de belirlenmiştir [11, 19-28]. Bununla birlikte cins üyelerinin kimyasal profilleri ve biyolojik aktiviteleri üzerine yapılan çalışmalar halen yeterli seviyede değildir.

Bu çalışmada $A$. baytopiae bitkisinin kök, gövde, yaprak ve tohumlarından elde edilen farklı ekstraktların (aseton, metanol ve su) antioksidan ve enzim inhibitör özellikleri araştırılarak biyolojik potansiyellerinin ortaya konulması amaçlanmıştır. Elde edilecek olan sonuçlar Asphodeline cinsi ve bu tür üzerine yeni bakış açılarının doğmasını sağlayacaktır.

\section{MATERYAL VE METOT}

\subsection{Bitki Materyali ve Ekstraktların Elde Edilmesi}

Asphodeline baytopiae örnekleri Mersin: GülnarAydıncık arasında gerçekleştirilen arazi çalışmasında 2014 yılında toplanmıştır (Gülnar ve Aydıncık arası, Gülnar'a 17 km'e kala, açık alanlar, GPS: $36^{\circ} 16^{\prime}$ 07' K, $33^{\circ} 22^{\prime} 11$ ' D, $751 \mathrm{~m}$, Toplayıc1 No: GZ-1436). Bitkinin toplandığ 1 alanda baskın tür olarak Asphodelus aestivus Brot. üyeleri gözlenmiştir. Toplanan örneklerin kök, gövde, yaprak ve tohum kısımları ayrılıp gölgede kurutuldu. Her bir kısım için aseton, metanol ve su özütleri elde edildi. Aseton ve metanol özütleri için sokslet aparatı kullanıldı ve $5 \mathrm{~g}$ bitkisel materyal bu çözücüler kullanılarak 6-8 saat süreyle ekstraksiyona tabi tutuldu. Ekstraklar süzüldü ve rotary-evaporatörde çözücüler uzaklaştırıldı. Su özütleri ise her bir kısım (5 g) için $250 \mathrm{ml}$ su ile yarım saat boyunca kaynatıldı. Süzülme işlemini takiben su özütleri liyofilize edildi. Tüm ekstraktlar analizlere kadar $+4{ }^{\circ} \mathrm{C}$ 'de saklandı.

\subsection{Toplam Fenolik ve Flavonoid İçerik}

A. baytopiae ekstraktlarının toplam fenolik ve flavonoid içerikleri spektrofotometrik olarak belirlendi ve içerikler fenolik için gallik asit (GAE) ve flavonoid için rutin (RE) kullanılarak hesaplandı [29].

\subsection{Antioksidan Kapasite Testleri}

A. baytopiae ekstraklarının antioksidan özellikleri farklı test sistemleri kullanılarak belirlenmiştir. $\mathrm{Bu}$ test sistemleri radikal süpürme aktiviteleri (DPPH ve ABTS), indirgeme gücü (FRAP ve CUPRAC), metal şelatlama ve fosfomolibdat testlerini içermektedir. Testlerin sonuçları standard maddelere eş değer olarak hesaplanmıştır (Trolox eşdeğeri: TE ve EDTA eşdeğeri: 
EDTAE). Bu test sistemlerine ait deneysel prosedürler önceki çalışmalarımızda rapor edilmiştir $[23,30]$.

\subsection{Enzim İnhibisyonuna Yönelik Testler}

A. baytopiae ekstraklarının enzim inhibitör özellikleri kolinesterazlar (AChE ve $\mathrm{BChE}$ ), tirozinaz, $\alpha$-amilaz ve $\alpha$-glukozidaz enzimleri kullanılarak belirlendi ve bu testlere ait deneysel prosedürler önceki çalışmalarımızda belirtildi $[18,30]$. Enzim inhibisyon sonuçlar1 standard eşdeğer olarak değerlendirildi (kolinesterazlar için galatamin (GALAE); tirozinaz için kojik asit (KAE); amilaz ve glukozidaz için akarboz (ACAE))

\section{5. İstatiksel değerlendirme}

Sonuçlar üç paralel ölçümün ortalaması ve standard sapmaları şeklinde verildi. Ekstraklar arasında her hangi bir fark olup olmadıkları tek yönlü varyans analizi (ANOVA, Tukey testi) ile belirlendi. Ayrica ekstraktlara uygulanan testler arasinda Pearson korelasyon analizleri yapıldı. İstatistiksel değerlendirmeler GraphPad Prism 9.0 programı kullanılarak gerçekleştirildi.

\section{BULGULAR}

Fenolik bileşikler sekonder metabolitler içerisinde sergiledikleri biyolojik aktiviteler ile en fazla dikkat çeken bileşiklerdendir. Yapılan çalışmalar fenolik bileşiklerin alımının sağlık üzerine pozitif etkilerini ortaya koymuştur [31, 32]. Bu nedenle bitkisel bir ekstraktın fenolik içeriğinin tespiti, ekstraktın potansiyelinin yorumlanmasında önemli bir parametredir. Bu amaçla A. baytopiae ekstraktlarının toplam fenolik ve flavonoid içerikleri spektrofotometrik metotlar ile belirlenmiş ve sonuçlar Tablo 1'de özetlenmiştir. En yüksek fenolik içerik gövde-aseton ekstrakt (73.57 mg GAE/g ekstrakt)'ında belirlenmiş ve bunu sirasiyla gövde-metanol $(68.38 \mathrm{mg}$ GAE/g ekstrakt) ve gövde-su (52.32 mg GAE/g ekstrakt) izlemiştir. Benzer şekilde toplam flavonoid içerikte en yüksek gövde-aseton (75.04 mg RE/g ekstrakt) ve gövde-metanol (74.23mg RE/g ekstrakt) ekstraktlarında belirlenmiştir. Toplam flavonoid içerik bakımından tüm bitki kısımlarında solventler aseton $>$ metanol $>$ su şeklinde sıralanabilir. Elde edilen sonuçlar açık bir şekilde fenolik ve flavonoid içeriklerin kullanılan bitki kısmı ve çözücüye bağlı olarak değiştiğini ortaya koymuştur. Çalışmamız sonuçlarını destekler nitelikte çeșitli çalışmalarda da benzer sonuçlar rapor edilmiştir [33-36]. Son yıllarda yapılan çalışmalar, spektrofotometrik içerik sonuçlarının kesinliği hakkında çeşitli kaygıların doğmasına yol açmıştır [37]. Özellikle, Folin-Ciocalteu reaktifinin sadece fenolikler tarafindan değil aynı zamanda peptidler tarafindan da indirgenmesi fenoliklerin seviyesi hakkında kesin bir değerlendirme yapılmasını sinırlamaktadır.
Tablo 1. A. baytopiae ekstraklarının toplam fenolik ve flavonoid içerikleri

\begin{tabular}{|c|c|c|c|}
\hline Çözücü & Kisım & $\begin{array}{l}\text { Toplam Fenolik } \\
\text { içerik (mg } \\
\text { GAE/g özüt) }\end{array}$ & $\begin{array}{l}\text { Toplam } \\
\text { Flavonoid } \\
\text { içeriği (mg RE/g } \\
\text { özüt) }\end{array}$ \\
\hline \multirow{4}{*}{ Aseton } & Gövde & $73.57 \pm 3.81^{\mathrm{a}^{*}}$ & $75.04 \pm 1.85^{\mathrm{a}}$ \\
\hline & Kök & $46.48 \pm 2.55^{\mathrm{bc}}$ & $58.44 \pm 0.80^{\mathrm{d}}$ \\
\hline & Tohum & $31.74 \pm 1.93^{\mathrm{e}}$ & $64.23 \pm 1.42^{\mathrm{bc}}$ \\
\hline & Yaprak & $48.20 \pm 1.23^{\mathrm{b}}$ & $67.19 \pm 2.89^{b}$ \\
\hline \multirow{4}{*}{ Metanol } & Gövde & $68.38 \pm 3.40^{\mathrm{a}}$ & $74.23 \pm 0.44^{\mathrm{a}}$ \\
\hline & Kök & $22.55 \pm 1.48^{\mathrm{fg}}$ & $17.30 \pm 0.71^{\mathrm{h}}$ \\
\hline & Tohum & $25.43 \pm 1.69^{f}$ & $46.42 \pm 2.32^{\mathrm{e}}$ \\
\hline & Yaprak & $32.58 \pm 1.29^{\mathrm{e}}$ & $60.39 \pm 1.63^{\mathrm{cd}}$ \\
\hline \multirow{4}{*}{ Su } & Gövde & $52.32 \pm 1.97^{b}$ & $30.20 \pm 0.60^{f}$ \\
\hline & Kök & $17.98 \pm 1.37^{\mathrm{g}}$ & $8.97 \pm 0.48^{i}$ \\
\hline & Tohum & $40.55 \pm 1.29^{\mathrm{cd}}$ & $22.24 \pm 0.88^{\mathrm{g}}$ \\
\hline & Yaprak & $37.65 \pm 1.28^{\mathrm{de}}$ & $57.26 \pm 0.78^{d}$ \\
\hline
\end{tabular}

Üç paralel ölçümün ortalaması \pm S.D. GAE: Gallik asit eşdeğeri; RE Rutin eşdeğeri. Aynı sütundaki farklı harfler ekstraklar arasındaki farkı gösterir $(p<0.05)$.

Antioksidan kapasitenin değerlendirilmesinde tek universal bir metot bulunmadı̆̆ 1 için bitkisel bir ekstraktın antioksidan profili farklı mekanizmaları içeren birden fazla test sistemi ile doğrulanmalıdır. $\mathrm{Bu}$ bağlamda, A. baytopiae ekstraktlarının antioksidan profilleri farklı test sistemleri ile araștırılmıș ve sonuçlar Tablo 2'de özetlenmiştir. DPPH ve ABTS radikalleri antioksidan kapasite çalışmalarında en sık kullanılan radikaller olup bitkisel ekstraktların radikal süpürme kapasitelerinin belirlenmesinde kullanılmaktadır. Çalışmamızda her iki radikal içinde en güçlü etkinlik gövde-metanol (DPPH: $65.57 \mathrm{mg}$ TE/g ekstrakt ve ABTS: $\quad 150.51 \mathrm{mg}$ TE/g ekstrakt) ekstraktında gözlenmiștir. Genel olarak tohum ekstraktları, tüm çözücülerde en düşük radikal süpürme aktiviteleri sergilemiştir. Metal iyonlarının indirgenme gücü antioksidan moleküllerin elektron verme yeteneklerinin değerlendirilmesinde önemli bir göstergedir. Bu amaçla çalışmamızda $\mathrm{Cu}^{+2}$ ve $\mathrm{Fe}^{+3}$ iyonlarının indirgenme yetenekleri sirasiyla CUPRAC ve FRAP testleri ile araştırılmıştır. En güçlü etkinlik CUPRAC testi için gövde-aseton (255.97 mg TE/g ekstrakt) ve FRAP testi için ise gövde-metanol (152.97 $\mathrm{mg} \mathrm{TE} / \mathrm{g}$ ekstrakt) ekstraklarında gözlenmiştir. Her iki test sistemi içinde tüm çözücülerde en güçlü aktivite gövdede elde edilmiştir. Ayrıca kök ve tohum ekstraktları genel olarak indirgeme gücü testlerinde düşük aktiviteler sergilemiştir. Radikal süpürme ve indirgeme gücü tayinine yönelik testlerin sonuçları birlikte değerlendirildiğinde toplam fenolik içerik sonuçları ile uyumlu oldukları gözlenmiştir. Uygulanan test sistemleri arasındaki ilişkiyi belirlemek için Pearson korelasyon testi yapılmış ve toplam fenolik içerik ile radikal süpürme ve indirgeme gücü testleri arasında pozitif bir korelasyon gözlenmiştir (Şekil 1). Çalışmamız sonuçlarını doğrular nitelikte çeşitli araştırmacılarda toplam fenolik içerik ve antioksidan özellikler arasındaki pozitif bir korelasyonun varlığını göstermiştir [38-40].

Fosfomolibdat testi asidik ortamda antioksidan bileşikler tarafından Mo (VI)'nın Mo (V)'e indirgenmesi ve oluşan koyu mavi renkli Mo (V)-fosfat kompleksinin absorbansinın $695 \quad$ nm'de okunmasina dayanmaktadir[41]. Fosfomolibdat test sisteminde 
fenolikler dışındaki antioksidan bileşiklerde etkili olduğu için bazı araștırmacılar tarafından bir toplam antioksidan metodu olarak kabul edilir. Diğer testlerden farklı olarak en yüksek etkinlik $3.35 \mathrm{mmol} \mathrm{TE} / \mathrm{g}$ ekstrakt ile yaprakasetonda gözlenmiştir. Bu ekstraktı sırasıyla gövdeaseton (3.12 mmol TE/g ekstrakt) ve tohum-aseton (2.46 mmol TE/g ekstrakt) izlemektedir. $\mathrm{Bu}$ sonuçlardan açıkça asetonun metanol ve suya kıyasla bu test sisteminde daha etkin olduğunu göstermektedir. Şekil 1 'de toplam fenolik içerik ve fosfomolibdat testi arasındaki korelasyona bakıldığında, bu iki test sistemi arasında zayıf bir ilişki olduğu ve bu durumun fenolikler dışındaki antioksidan bileşiklerin varlığı ile açıklanabileceği sonucu çıkarılabilir. Benzer şekilde çeşitli araştırmacılarda bu test sistemi ile toplam fenolik içerik arasında düşük korelasyon değerlerini rapor etmiştir [42-44].

Geçiş metallerinin şelatlanması Fenton reaksiyonu ile hidroksil radikali üretiminin durdurulmasında oldukça önemli bir yer tutmaktadır. Bu nedenle şelatlayıcı ajanlar önemli antioksidan bileşikler olarak kabul edilirler [45]. Çalışmamızda A. baytopiae ekstraktlarının metal şelatlama yetenekleri ferrozin testi ile belirlenmiş ve sonuçlar Tablo 2'de verilmiştir. En güçlü şelatlama kapasitesine sahip ekstrakt gövde-su (61.02 mg EDTAE/g ekstrakt) olup, bunu sirasıyla gövde-aseton (57.73 mg EDTAE/g ekstrakt) ve yaprak-aseton (52.67 mg EDTAE/g ekstrakt) izlemektedir. Metal şelatlama aktivitesi bakımından en zayıf ekstrakt ise kök-su (4.89 mg EDTAE/g ekstrakt) olarak bulunmuştur. Yapılan çeşitli çalışmalarda metal şelatlama yeteneğinin fenolik bileşiklerin antioksidan mekanizmaları arasında minör bir yol olduğu belirtilmiş [46, 47] ve bunu doğrular nitelikte çalışmamızda toplam fenolik içerik ile metal şelatlama yeteneği arasında zayıf bir ilişki gözlenmiştir (Şekil 1).

Enzimler, ilaç dizaynı ve geliştirilmesinde ana hedefler konumunda olup, eczane raflarındaki ilaçların büyük bir çoğunluğu enzim inhibitörleri olarak görev yapmaktadırlar. Enzim inhibisyonu, bazı hastalıkların gelişimine doğrudan veya dolaylı olarak katkı sağlayan enzimlerin inhibe edilmesi ve gözlenen patolojik bulguların hafifletilmesine dayanır. $\mathrm{Bu}$ amaçla Alzheimer hastalığında, bilinçsel faaliyetleri kontrol etmek için kolinesterazlar [48], şeker hastalığında kan şeker seviyelerini kontrol etmek için amilaz ve glukozidaz [49] ile deri hastalıkları için tirozinaz [50] enzimleri farmasötik hedeflerdir. Bu noktadan hareketle ilaç endüstrisi bu enzimleri inhibe edecek çok sayıda sentetik ajanlar üretmiştir. Ancak bu sentetiklerin başta gastrointestinal bozukluklar ve toksik özellikleri olmak üzere sergiledikleri yan etkiler bunların kullanımlarını kaygılı hale getirmiştir [51-53]. $\mathrm{Bu}$ nedenle bu sentetiklerin yerini alabilecek doğal kaynaklı güvenilir ve etkili ajanlara ihtiyaç vardır. Bu amaçla mevcut çalışmamızda A. baytopiae ekstraklarının inhibitör özellikleri kolinesterazlar (AChE ve BChE), tirozinaz, amilaz ve glukozidaz'a karşı araştırılmıştır (Tablo 3). Kolinesteraz inhibisyonu bakımından en güçlü ekstrakt olarak kök-aseton (AChE: 4.96 mg GALAE/g ekstrakt ve BChE: $7.84 \mathrm{mg}$ GALAE/g ekstrakt). Genel olarak, her bir kısım için aseton ekstraktları metanole kıyasla daha güçlü kolinesteraz inhibitör özellik sergilemiştir. Bununla birlikte su özütlerinin hiçbiri kolinesterazlara karşı etkili bulunmamıştır. Melanin sentezinde anahtar enzim olan tirozinaz enzimi üzerine çalışılan ekstraktların potansiyelleri değerlendirildiğinde en güçlü ekstrakt olarak kök-metanol (74.64 mg KAE/g ekstrakt) bulunmuş ve bunu sırasıyla yaprak-metanol $(68.17 \mathrm{mg}$ $\mathrm{KAE} / \mathrm{g}$ ekstrakt) ve tohum-metanol (67.78 mg KAE/g ekstrakt) izlemektedir. Tüm kısımlar için en zayıf ekstraktlar ise su ekstrakları olarak bulunmuş ve yapraksu ekstraktında herhangi bir tirozinaz inhibisyonu gözlenmemiştir. Benzer şekilde amilaz ve glukozidaz inhibisyonları bakımından da aseton ve metanol ekstrakları, su ekstraklarına kıyasla güçlü aktiviteler sergilemiştir. Su özütlerinin hiçbiri glukozidaz üzerine herhangi bir inhibitör etki sergilememiștir. Amilaz inhibisyonu bakımından en güçlü ekstrakt yaprak-aseton (0.79 mmol ACAE/g ekstrakt) ve gövde-aseton (0.77 mmol ACAE/g ekstrakt); glukozidaz bakımından ise tohum-aseton (4.65 mmol ACAE/g ekstrakt) ve yaprakaseton (4.34 mmol ACAE/g) tespit edilmiștir. Asphodeline üyeleri için önceki çalışmalarda da enzim inhibitörleri olarak önemli aktiviteler belirlenmiş [11, 19-21, 23, 24] ve bu noktada bu cinsin üyeleri farmasötik endüstri için değerli bir ham madde kaynağ olarak düşünülebilir.

\section{SONUÇ}

Mevcut çalışmamız A. baytopiae ekstraktlarının biyolojik aktiviteleri hakkında önemli bilgiler sağlamakta ve elde edilen sonuçlar A. baytopiae'nin doğal ajanların önemli bir kaynağı olarak farmasötik ve gida endüstrilerinde değerli olabileceğini ortaya koymuştur. Özellikle A. baytopiae'nin farklı kısımlarından elde edilen aseton ve metanol ekstrakları biyolojik aktivite bakımından güçlü özellikler sergilemiştir. Ülkemiz sahip olduğu bitki çeşitliliği ve bunların geleneksel kullanımları noktasında önemli bir konumda bulunmakta ve araștırılmamış bitki türleri üzerine yapılacak çalışmalarla bu potansiyelin daha fazla gün yüzüne çıkması sağlanmalıdır. $\mathrm{Bu}$ noktadan hareketle çalışmamız A. baytopiae üzerine bir bilimsel başlangıç noktası oluşturacak ve ileride bu tür üzerine yapılacak yeni çalışmalara $1 s ̧ ı$ k tutacaktır. 
Tablo 2. A. baytopiae ekstraklarının antioksidan özellikleri

\begin{tabular}{|c|c|c|c|c|c|c|c|}
\hline Çözücü & Kisım & $\begin{array}{c}\text { DPPH süpürücü } \\
\text { aktivite (mg TE/g) }\end{array}$ & $\begin{array}{c}\text { ABTS süpürücü aktivite } \\
\text { (mg TE/g) }\end{array}$ & $\begin{array}{c}\text { FRAP } \\
(\mathrm{mg} \text { TE/g) }\end{array}$ & $\begin{array}{l}\text { CUPRAC } \\
(\mathrm{mg} \text { TE/g) }\end{array}$ & $\begin{array}{c}\begin{array}{c}\text { Fosfomolibdat } \\
(\mathrm{mmol} \text { TE/g) }\end{array} \\
\end{array}$ & $\begin{array}{l}\text { Metal şelatlama } \\
\text { (mg EDTAE/g) }\end{array}$ \\
\hline \multirow{4}{*}{ Aseton } & Gövde & $55.04 \pm 7.01^{\mathrm{b}^{*}}$ & $121.24 \pm 3.44^{\mathrm{b}}$ & $135.48 \pm 2.31^{\mathrm{b}}$ & $255.97 \pm 7.53^{\mathrm{a}}$ & $3.12 \pm 0.10^{\mathrm{b}}$ & $57.73 \pm 4.05^{\mathrm{a}}$ \\
\hline & Kök & $62.89 \pm 4.87^{\mathrm{ab}}$ & $109.02 \pm 3.16^{\mathrm{c}}$ & $100.03 \pm 5.93^{\mathrm{d}}$ & $196.81 \pm 5.43^{\mathrm{c}}$ & $2.40 \pm 0.13^{\text {cd }}$ & $24.68 \pm 0.91^{f}$ \\
\hline & Tohum & $9.39 \pm 0.41^{\mathrm{efg}}$ & $44.77 \pm 0.57^{\mathrm{g}}$ & $49.77 \pm 0.74^{g}$ & $143.88 \pm 4.49^{\mathrm{d}}$ & $2.46 \pm 0.02^{\mathrm{c}}$ & $46.76 \pm 0.30^{\mathrm{c}}$ \\
\hline & Yaprak & $40.67 \pm 2.09^{c}$ & $66.35 \pm 0.74^{f}$ & $85.25 \pm 0.66^{\mathrm{e}}$ & $184.72 \pm 3.63^{c}$ & $3.35 \pm 0.12^{\mathrm{a}}$ & $52.67 \pm 0.56^{b}$ \\
\hline \multirow{5}{*}{ Metanol } & & & & & & & \\
\hline & Gövde & $65.57 \pm 4.35^{\mathrm{a}}$ & $150.51 \pm 6.39^{\mathrm{a}}$ & $152.97 \pm 3.72^{\mathrm{a}}$ & $237.35 \pm 8.54^{b}$ & $2.19 \pm 0.06^{\mathrm{de}}$ & $10.96 \pm 0.41^{g}$ \\
\hline & Kök & $16.00 \pm 0.53^{\mathrm{ef}}$ & $45.36 \pm 0.38^{g}$ & $43.79 \pm 2.47^{\text {gh }}$ & $80.14 \pm 4.51^{g}$ & $1.88 \pm 0.03^{f}$ & $21.93 \pm 0.84^{f}$ \\
\hline & Tohum & $7.41 \pm 0.34^{\mathrm{fg}}$ & $46.64 \pm 0.97^{g}$ & $44.12 \pm 2.08^{\text {gh }}$ & $102.93 \pm 3.44^{\mathrm{f}}$ & $1.90 \pm 0.06^{\mathrm{f}}$ & $30.30 \pm 0.07^{\mathrm{e}}$ \\
\hline & Yaprak & $28.47 \pm 1.65$ & $67.43 \pm 0.99^{f}$ & $76.30 \pm 2.05^{\mathrm{f}}$ & $125.21 \pm 3.25^{\mathrm{e}}$ & $2.08 \pm 0.13^{\text {ef }}$ & $12.92 \pm 0.49^{g}$ \\
\hline \multirow{4}{*}{$\mathrm{Su}$} & Gövde & $56.33 \pm 3.15^{\mathrm{ab}}$ & $115.23 \pm 7.79^{\mathrm{bc}}$ & $109.18 \pm 3.83^{\mathrm{c}}$ & $158.95 \pm 4.89^{d}$ & $1.44 \pm 0.03^{\mathrm{g}}$ & $61.02 \pm 2.84^{\mathrm{a}}$ \\
\hline & Kök & $4.40 \pm 0.17^{\mathrm{g}}$ & $23.28 \pm 0.90^{\mathrm{h}}$ & $36.98 \pm 1.94^{\mathrm{h}}$ & $60.91 \pm 4.68^{h}$ & $2.48 \pm 0.02^{\mathrm{c}}$ & $4.89 \pm 0.21^{\mathrm{h}}$ \\
\hline & Tohum & $18.45 \pm 0.43^{\mathrm{e}}$ & $81.06 \pm 4.26^{\mathrm{e}}$ & $46.27 \pm 1.42^{\mathrm{g}}$ & $78.34 \pm 5.36^{\mathrm{h}}$ & $0.72 \pm 0.01^{\mathrm{h}}$ & $41.76 \pm 0.29^{\mathrm{d}}$ \\
\hline & Yaprak & $62.89 \pm 5.00^{\mathrm{ab}}$ & $97.36 \pm 8.41^{\mathrm{d}}$ & $87.80 \pm 2.77^{\mathrm{e}}$ & $127.83 \pm 2.64^{\mathrm{e}}$ & $1.52 \pm 0.01^{\mathrm{g}}$ & $47.58 \pm 2.04^{\mathrm{c}}$ \\
\hline
\end{tabular}

"Üç paralel ölçümün ortalaması \pm S.D. TE: Troloks eşdeğeri; EDTAE; EDTA eşdeğeri. Aynı sütundaki farklı harfler ekstraklar arasındaki farkı gösterir $(p<0.05)$.

Tablo 3. A. baytopiae ekstraklarını enzim inhibitor özellikleri

\begin{tabular}{|c|c|c|c|c|c|c|}
\hline Çözücü & Kısım & $\begin{array}{l}\text { AChE inhibisyonu (mg } \\
\text { GALAE/g) }\end{array}$ & $\begin{array}{c}\text { BChE inhibisyonu (mg } \\
\text { GALAE/g) }\end{array}$ & $\begin{array}{l}\text { Tirozinaz inhibisyonu } \\
\text { (mg KAE/g) }\end{array}$ & $\begin{array}{c}\text { Amilaz } \\
\text { inhibisyonu } \\
(\text { mmol ACAE/g) }\end{array}$ & $\begin{array}{c}\text { Glukozidaz } \\
\text { inhibisyonu (mmol } \\
\text { ACAE } / \mathrm{g})\end{array}$ \\
\hline \multirow{4}{*}{ Aseton } & Gövde & $3.71 \pm 0.08^{\mathrm{bc}}$ & $7.29 \pm 0.01^{\mathrm{b}}$ & $54.54 \pm 1.22^{\mathrm{c}}$ & $0.77 \pm 0.01^{\mathrm{a}}$ & $3.42 \pm 0.03^{\mathrm{c}}$ \\
\hline & Kök & $4.96 \pm 0.09^{\mathrm{a}}$ & $7.84 \pm 0.30^{\mathrm{a}}$ & $65.21 \pm 0.87^{\mathrm{b}}$ & $0.52 \pm 0.01^{\mathrm{c}}$ & $3.86 \pm 0.73^{\mathrm{abc}}$ \\
\hline & Tohum & $4.65 \pm 0.33^{\mathrm{a}}$ & $5.58 \pm 0.01^{\mathrm{e}}$ & $65.29 \pm 2.73^{\mathrm{b}}$ & $0.64 \pm 0.01^{\mathrm{b}}$ & $4.65 \pm 0.15^{\mathrm{a}}$ \\
\hline & Yaprak & $3.96 \pm 0.03^{\mathrm{b}}$ & $6.02 \pm 0.07^{\mathrm{d}}$ & $62.95 \pm 2.87^{\mathrm{b}}$ & $0.79 \pm 0.01^{\mathrm{a}}$ & $4.34 \pm 0.29^{\mathrm{ab}}$ \\
\hline & & & & & & \\
\hline \multirow{4}{*}{ Metanol } & Gövde & $3.42 \pm 0.01^{\mathrm{c}}$ & $4.44 \pm 0.23^{\mathrm{g}}$ & $61.63 \pm 3.47^{\mathrm{b}}$ & $0.35 \pm 0.01^{\mathrm{e}}$ & $3.62 \pm 0.30^{\mathrm{bc}}$ \\
\hline & Kök & $4.86 \pm 0.01^{\mathrm{a}}$ & $6.61 \pm 0.06^{\mathrm{c}}$ & $74.64 \pm 4.30^{\mathrm{a}}$ & $0.33 \pm 0.01^{\mathrm{e}}$ & $3.59 \pm 0.02^{\mathrm{bc}}$ \\
\hline & Tohum & $4.82 \pm 0.11^{\mathrm{a}}$ & $5.23 \pm 0.04^{\mathrm{f}}$ & $67.78 \pm 3.55^{\mathrm{ab}}$ & $0.41 \pm 0.01^{\mathrm{d}}$ & $4.04 \pm 0.41^{\mathrm{abc}}$ \\
\hline & Yaprak & $3.56 \pm 0.04^{\mathrm{c}}$ & $4.08 \pm 0.03^{\mathrm{h}}$ & $68.17 \pm 2.12^{\mathrm{ab}}$ & $0.30 \pm 0.01^{\mathrm{f}}$ & $3.84 \pm 0.34^{\mathrm{abc}}$ \\
\hline & & & & & & \\
\hline \multirow{4}{*}{ Su } & Gövde & na & na & $15.97 \pm 0.33^{\mathrm{d}}$ & $0.05 \pm 0.01^{\mathrm{g}}$ & na \\
\hline & Kök & na & na & $13.48 \pm 0.54^{\mathrm{d}}$ & $0.05 \pm 0.01^{\mathrm{g}}$ & na \\
\hline & Tohum & na & na & $4.83 \pm 0.12^{\mathrm{e}}$ & $0.02 \pm 0.01^{\mathrm{h}}$ & na \\
\hline & Yaprak & na & na & na & na & na \\
\hline
\end{tabular}

"Üç paralel ölçümün ortalamasıะS.D. GALAE: Galatamin eşdeğeri; KAE: Kojik asit eşdeğeri; ACAE: Akarboz eşdeğeri; na: aktivite gözlenmedi. Aynı sütundaki farklı harfler ekstraklar arasındaki farkı gösterir $(p<0.05)$.

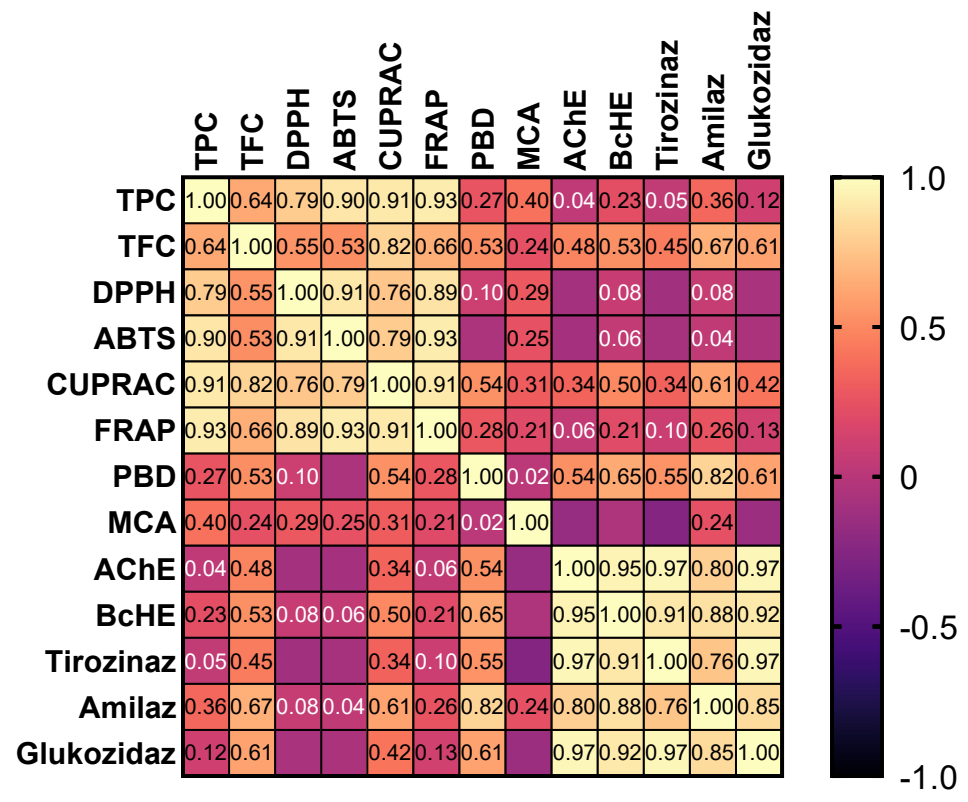

Şekil 1. Biyolojik aktivite testleri arasında Pearson korelasyon değerleri $(\mathrm{p}<0.05)$. 


\section{KAYNAKLAR}

[1] Kaiser AB, Zhang N, Der Pluijm WV. Global Prevalence of Type 2 Diabetes over the Next Ten Years (2018-2028). Diabetes. 2018;67(Supplement 1):202-LB.

[2] Alzheimer's Association. 2019 Alzheimer's disease facts and figures. Alzheimer's \& Dementia. 2019;15(3):321-87.

[3] Chen Y, Kirchmair J. Cheminformatics in Natural Product-Based Drug Discovery. Molecular Informatics. 2020;39(12):2000171.

[4] Chávez-Hernández AL, Sánchez-Cruz N, MedinaFranco JL. Fragment Library of Natural Products and Compound Databases for Drug Discovery. Biomolecules. 2020;10(11):1518.

[5] Noroozi J, Zare G, Sherafati M, Mahmoodi M, Moser D, Asgarpour Z, et al. Patterns of endemism in Turkey, the meeting point of three global biodiversity hotspots, based on three diverse families of vascular plants. Frontiers in Ecology and Evolution. 2019;7:159.

[6] Şenkardeş İ, Bulut G, Doğan A, Tuzlacı E. An Ethnobotanical Analysis on Wild Edible Plants of the Turkish Asteraceae Taxa. Agriculturae Conspectus Scientificus. 2019;84(1):17-28.

[7] Sezik E, Yeşilada E, Honda G, Takaishi Y, Takeda $\mathrm{Y}$, Tanaka T. Traditional medicine in Turkey $\mathrm{X}$. Folk medicine in Central Anatolia. Journal of Ethnopharmacology. 2001;75(2):95-115.

[8] Güneş S, Savran A, Paksoy MY, Koşar M, Çakılcıoğlu U. Ethnopharmacological survey of medicinal plants in Karaisalı and its surrounding (Adana-Turkey). Journal of Herbal Medicine. 2017;8:68-75.

[9] The Plant List. Version 1.1. Published on the Internet; http://www.theplantlist.org/ (accessed 1st January). 2013.

[10] Güner A, Aslan S, Ekim T, Vural M, Babaç M. Türkiye Bitkileri Listesi. Damarlı Bitkiler, Nezahat Gökyiğit Botanik Bahçesi ve Flora Araştırmaları Derneği Yayını. 2012(s 262).

[11] Melucci D, Locatelli M, Locatelli C, Zappi A, De Laurentiis F, Carradori S, et al. A comparative assessment of biological effects and chemical profile of Italian Asphodeline lutea extracts. Molecules. 2018;23(2):461.

[12] Kargığlu M, Cenkci S, Serteser A, Evliyaoğlu N, Konuk M, Kök MŞ, et al. An ethnobotanical survey of inner-West Anatolia, Turkey. Human Ecology. 2008;36(5):763-77.

[13] Sargin SA, Büyükcengiz M. Plants used in ethnomedicinal practices in Gulnar district of Mersin, Turkey. Journal of Herbal Medicine. 2019;15:100224.

[14] Altundag E, Ozturk M. Ethnomedicinal studies on the plant resources of east Anatolia, Turkey. Procedia-Social and Behavioral Sciences. 2011;19:756-77.

[15] ERARSLAN ZB, ECEVIT-GENÇ G, Kültür Ş. Medicinal plants traditionally used to treat skin diseases in Turkey-eczema, psoriasis, vitiligo.
Ankara Üniversitesi Eczacılık Fakültesi Dergisi. 2020;44(1):137-66.

[16] Tuzlacı E. Türkiyenin Çiriş otları (I). Marmara Üniversitesi Eczacılık Fakültesi Dergisi. 1985;1: 69-89.

[17] Tuzlacı E. Asphodeline (Liliaceae) taksonlarının Türkiye'deki yayılışları. Doğa Botanik Dergisi. 1988;12(1):71-84.

[18] Zengin G. A study on in vitro enzyme inhibitory properties of Asphodeline anatolica: New sources of natural inhibitors for public health problems. Industrial Crops and Products. 2016;83:39-43.

[19] Locatelli M, Zengin G, Uysal A, Carradori S, De Luca E, Bellagamba $G$, et al. Multicomponent pattern and biological activities of seven Asphodeline taxa: potential sources of naturalfunctional ingredients for bioactive formulations. Journal of enzyme inhibition and medicinal chemistry. 2017;32(1):60-7.

[20] Zengin G, Locatelli M, Ceylan R, Aktumsek A. Anthraquinone profile, antioxidant and enzyme inhibitory effect of root extracts of eight Asphodeline taxa from Turkey: can Asphodeline roots be considered as a new source of natural compounds? Journal of enzyme inhibition and medicinal chemistry. 2016;31(5):754-9.

[21] Zengin G, Menghini L, Malatesta L, De Luca E, Bellagamba G, Uysal S, et al. Comparative study of biological activities and multicomponent pattern of two wild Turkish species: Asphodeline anatolica and Potentilla speciosa. Journal of Enzyme Inhibition and Medicinal Chemistry. 2016;31(sup1):203-8

[22] Lazarova I, Zengin G, Aktumsek A, Gevrenova R, Ceylan R, Uysal S. HPLC-DAD analysis of phenolic compounds and antioxidant properties of Asphodeline lutea roots from Bulgaria and Turkey. Industrial Crops and Products. 2014;61:438-41.

[23] Locatelli M, Yerlikaya S, Baloglu MC, Zengin G, Altunoglu YC, Cacciagrano F, et al. Investigations into the therapeutic potential of Asphodeline liburnica roots: In vitro and in silico biochemical and toxicological perspectives. Food and chemical toxicology. 2018;120:172-82.

[24] Lazarova I, Zengin G, Bender O, ZhelevaDimitrova D, Uysal S, Ceylan R, et al. A comparative study of Bulgarian and Turkish Asphodeline lutea root extracts: HPLC-UV profiles, enzyme inhibitory potentials and antiproliferative activities against MCF-7 and MCF$10 \mathrm{~A}$ cell lines. Journal of functional foods. 2015;15:254-63.

[25] Lazarova I, Simeonova R, Vitcheva V, KondevaBurdina M, Gevrenova R, Zheleva-Dimitrova D, et al. Hepatoprotective and antioxidant potential of Asphodeline lutea (L.) Rchb. roots extract in experimental models in vitro/in vivo. Biomedicine \& Pharmacotherapy. 2016;83:70-8.

[26] Lazarova I, Zengin G, Gevrenova R, Nedialkov P, Aneva I, Aumeeruddy MZ, et al. A comparative study of UHPLC/Orbitrap MS metabolomics profiles and biological properties of Asphodeline taurica from Bulgaria and Turkey. Journal of 
Pharmaceutical and Biomedical Analysis. 2019;168:174-80.

[27] Marino A, Zengin G, Nostro A, Ginestra G, Dugo $\mathrm{P}$, Cacciola $\mathrm{F}$, et al. Antimicrobial activities, toxicity and phenolic composition of Asphodeline anatolica E. Tuzlaci leaf extracts from Turkey. Natural product research. 2016;30(22):2620-3.

[28] Uysal A, Lazarova I, Zengin G, Gunes E, Aktumsek A, Gevrenova R. New Perspectives on Asphodeline lutea from Bulgaria and Turkey: Antimutagenic, Anti-microbial and Anti-methicillin Resistant Staphylococcus aureus (MRSA) Activity. Journal of Pharmaceutical Research International. 2016:1-10.

[29] Zengin G, Aktumsek A. Investigation of antioxidant potentials of solvent extracts from different anatomical parts of Asphodeline anatolica E. Tuzlaci: An endemic plant to Turkey. African Journal of Traditional, Complementary and Alternative Medicines. 2014;11(2):481-8.

[30] Uysal S, Zengin G, Locatelli M, Bahadori MB, Mocan A, Bellagamba G, et al. Cytotoxic and enzyme inhibitory potential of two Potentilla species (P. speciosa L. and P. reptans Willd.) and their chemical composition. Frontiers in pharmacology. 2017;8:290.

[31] Zhang B, Zhang Y, Li H, Deng Z, Tsao R. A review on insoluble-bound phenolics in plant-based food matrix and their contribution to human health with future perspectives. Trends in Food Science \& Technology. 2020;105:347-62.

[32] Shahidi F, Ambigaipalan P. Phenolics and polyphenolics in foods, beverages and spices: Antioxidant activity and health effects - A review. Journal of Functional Foods. 2015;18:820-97.

[33] Patial PK, Cannoo DS. Evaluation of volatile compounds, phenolic acids, antioxidant potential and DFT study of essential oils from different parts of Araucaria columnaris (G. Forst.) Hook. from India. Food and Chemical Toxicology. 2020;141:111376.

[34] Belhaoues S, Amri S, Bensouilah M. Major phenolic compounds, antioxidant and antibacterial activities of Anthemis praecox Link aerial parts. South African Journal of Botany. 2020;131:200-5.

[35] Barbouchi M, Elamrani K, El Idrissi M, Choukrad Mb. A comparative study on phytochemical screening, quantification of phenolic contents and antioxidant properties of different solvent extracts from various parts of Pistacia lentiscus L. Journal of King Saud University - Science. 2020;32(1):3026.

[36] Alnuqaydan AM, Rah B. Comparative assessment of biological activities of different parts of halophytic plant Tamarix articulata (T. articulata) growing in Saudi Arabia. Saudi Journal of Biological Sciences. 2020;27(10):2586-92.

[37] Sánchez-Rangel JC, Benavides J, Heredia JB, Cisneros-Zevallos L, Jacobo-Velázquez DA. The Folin-Ciocalteu assay revisited: improvement of its specificity for total phenolic content determination. Analytical Methods. 2013;5(21):5990-9.
[38] Wu L, Wu W, Cai Y, Li C, Wang L. HPLC fingerprinting-based multivariate analysis of phenolic compounds in mango leaves varieties: Correlation to their antioxidant activity and in silico $\alpha$-glucoidase inhibitory ability. Journal of Pharmaceutical and Biomedical Analysis. 2020;191:113616.

[39] Lou X, Xu H, Hanna M, Yuan L. Identification and quantification of free, esterified, glycosylated and insoluble-bound phenolic compounds in hawthorn berry fruit (Crataegus pinnatifida) and antioxidant activity evaluation. LWT. 2020;130:109643.

[40] Sarikurkcu C, Andrade JC, Ozer MS, de Lima Silva JMF, Ceylan O, de Sousa EO, et al. LC-MS/MS profiles and interrelationships between the enzyme inhibition activity, total phenolic content and antioxidant potential of Micromeria nervosa extracts. Food Chemistry. 2020;328:126930.

[41] Prieto P, Pineda M, Aguilar M. Spectrophotometric quantitation of antioxidant capacity through the formation of a phosphomolybdenum complex: specific application to the determination of vitamin E. Anal Biochem. 1999;269(2):337-41.

[42] Zengin G, Bulut G, Mollica A, Haznedaroglu MZ, Dogan A, Aktumsek A. Bioactivities of Achillea phrygia and Bupleurum croceum based on the composition of phenolic compounds: In vitro and in silico approaches. Food and Chemical Toxicology. 2017; 107:597-608.

[43] Benabderrahim MA, Elfalleh W, Sarikurkcu C, Sarikurkcu RB. Biological activities and phytochemical composition of organs from Loranthus europaeus. Industrial Crops and Products. 2019;141:111772.

[44] Etienne OK, Dall'Acqua S, Sinan KI, Ferrarese I, Sut S, Sadeer NB, et al. Chemical characterization, antioxidant and enzyme inhibitory effects of Mitracarpus hirtus extracts. Journal of Pharmaceutical and Biomedical Analysis. 2020:113799.

[45] Bibi Sadeer N, Montesano D, Albrizio S, Zengin G, Mahomoodally MF. The Versatility of Antioxidant Assays in Food Science and Safety-Chemistry, Applications, Strengths, and Limitations. Antioxidants. 2020;9(8):709.

[46] Rice-Evans C, Miller N, Paganga G. Antioxidant properties of phenolic compounds. Trends in plant science. 1997;2(4):152-9.

[47] Wang T, Jonsdottir R, Ólafsdóttir G. Total phenolic compounds, radical scavenging and metal chelation of extracts from Icelandic seaweeds. Food chemistry. 2009;116(1):240-8.

[48] Mishra P, Kumar A, Panda G. Anti-cholinesterase hybrids as multi-target-directed ligands against Alzheimer's disease (1998-2018). Bioorganic \& Medicinal Chemistry. 2019;27(6):895-930.

[49] Papoutsis K, Zhang J, Bowyer MC, Brunton N, Gibney ER, Lyng J. Fruit, vegetables, and mushrooms for the preparation of extracts with $\alpha$ amylase and $\alpha$-glucosidase inhibition properties: A review. Food Chemistry. 2021;338:128119.

[50] Mukherjee PK, Biswas R, Sharma A, Banerjee S, Biswas S, Katiyar CK. Validation of medicinal 
herbs for anti-tyrosinase potential. Journal of Herbal Medicine. 2018;14:1-16.

[51] Dhameja M, Gupta P. Synthetic heterocyclic candidates as promising $\alpha$-glucosidase inhibitors: An overview. European Journal of Medicinal Chemistry. 2019;176:343-77.

[52] Marucci G, Buccioni M, Ben DD, Lambertucci C, Volpini R, Amenta F. Efficacy of acetylcholinesterase inhibitors in Alzheimer's disease. Neuropharmacology. 2020:108352.

[53] Saeedi M, Eslamifar M, Khezri K. Kojic acid applications in cosmetic and pharmaceutical preparations. Biomedicine \& Pharmacotherapy. 2019;110:582-93. 